\title{
The Danger of Deference: A Case of Polite Governance
}

\author{
JAMES T. MINOR \\ Michigan State University \\ WILLIAM G. TIERNEY \\ University of Southern California
}

Over the past decade numerous arguments have been put forth that campus governance needs to be reformed to meet new challenges. Rethinking admission standards, implementing distance learning, increasing fund-raising, diversifying the faculty, and creating external partnerships are just a few issues that demand timely and informed decisions. For some individuals, these topics create decision-making contexts that stand in contradiction to the tradition of shared governance. To others, shared governance becomes an obstacle to effective decision-making rather than its vehicle. This study explores a campus where the perception is that "governance works." The university enjoys a stable organizational history, climate, and administration that are circumscribed by what we will define as a culture of deference. The institution, however, does not appear to struggle over questions of quality such as how they might improve and what actions might create these improvements. The authors question whether a decision-making culture of deference promotes effective campus governance. The text begins with a discussion of what the authors mean by effective governance within an organization's culture and they then present data from an intensive case study of one campus. The authors conclude that cooperation and trust are foundational but insufficient indicators of good governance.

Over the past decade numerous arguments have been put forth that campus governance needs to be revised to meet new challenges (i.e., Association of Governing Boards of Universities and Colleges, 1996). Rethinking admission standards, implementing distance learning, increasing fund-raising, diversifying the faculty, and creating external partnerships are just a few

This article examines the use of cultural perspectives for assessing the quality of university governance. The authors argue that outcomes are more useful indicators of effective governance rather than the amiability of campus constituents.

Teachers College Record Volume 107, Number 1, January 2005, pp. 137-156

Copyright (C) by Teachers College, Columbia University

$0161-4681$ 
issues that demand timely and informed decisions. For some individuals, these topics create decision-making contexts that stand in contradiction to the tradition of shared governance (Baldwin \& Leslie, 2001; Benjamin \& Carroll, 1999). To others, shared governance becomes an obstacle to effective decision making rather than its vehicle.

From time to time one hears about a president who has received a vote of no confidence from the campus senate, or a senate that is dissolved by the president. Such cases exemplify campuses with troubled governance. However, dramatic examples of this kind are rare. The larger problem pertaining to shared governance rests with the ability to make decisions intended to improve the quality of the institution that have the sustained input and support of multiple groups rather than sporadically involved or disengaged constituencies. In a recent national survey of four-year institutions we found that more than $80 \%$ of campus constituents believe that shared governance is an important part of their institution's value and identity. Yet more than $50 \%$ percent of the faculty expresses dissatisfaction with the way shared governance is employed (Tierney \& Minor, 2003). Based on these findings and the case study that will be discussed here, we suggest that one challenge of shared governance lies with cultural processes used to reach decisions. Although structural aspects of governance are important, they alone do not fully explain the problems that exist. Vitriolic statements that call for the elimination or diminution of shared governance do not reflect the broad support this form of governance has on campuses across the country (Carlin, 1999). At the same time, many in higher education believe that shared governance can be improved, and they ask whether the presidency should be strengthened or the faculty's role lessened. The question revolves around how academic leaders might improve governance for the dynamic contexts in which academe currently exists. The answer is twofold. First, we suggest that to improve governance one needs to understand the cultural processes at work in organizational life. Second we argue that an organization's participants need to attend to how those processes that pertain to governance improve the quality of the academic community.

Apart from the debate about why governance fails, research on decisionmaking, culture, and institutional performance is limited (Kezar \& Eckel, 2004; Tierney, in press). If one assumes that faculty involvement in decision-making affects institutional performance, then what aspects of faculty participation are important to sustain in the shared governance process and what aspects might change? We argue that the answer to that question centers on definitions of quality and how effective governance improves the quality of the institution.

This study explores a campus where the perception is that "governance works." The university enjoys a stable organizational history, climate, and administration that is circumscribed by what we will define as a culture of 
deference. Everyone, ostensibly, gets along. At the same time, the institution does not appear to struggle over questions of quality such as how they might improve and what actions might create these improvements. We question whether or not a decision-making culture of deference promotes effective campus governance.

We begin with a discussion of what we mean by effective governance within an organization's culture and then present data from a case study of one campus. We conclude with an analysis of the data and argue that cooperation and trust are foundational but insufficient indicators of good governance. For the purpose of this study we focus on governance that involves the faculty and administration - saving discussions about boardlevel governance and student governance for subsequent investigations.

\section{RETHINKING GOVERNANCE}

\section{USING FRAMES}

One central precept shared among higher education scholars is that universities, as organizations, can be interpreted using multiple theoretical frames. These frames represent adaptations from the larger body of organizational literature to account for the unique nature of colleges and universities (Cohen \& March, 1974; Kuh \& Whitt, 1988; Masland 1985; Mintzberg, 1979; Peterson, 1985). Universities, unlike business and industry organizations, are said to have ambiguous goals, use non-routine technology, and exhibit high levels of professional autonomy (Baldridge, Curtis, Ecker, \& Riley, 1977). Additionally, it is well known that colleges and universities have distinct cultures, histories, and operate in various social and political contexts (Clark, 1970). Consequently, discussions about university activity usually take place within one or another theoretical frame, which helps understand various aspects of the organization.

Concerning governance, scholars have also used various theoretical frames to explain university decision making. Collegial, political, bureaucratic, and cultural foundations each lend different perspectives on governance. Yet, the notion that no single theoretical perspective can fully explain university activity is a well accepted. Instead, it is often useful to employ multiple perspectives to understand university governance and decision making. Birnbaum (1988) uses four theoretical frames (collegial, bureaucratic, political, and anarchical) which are used comparatively to understand "how colleges work." In a similar vein, for the purpose of this study we call upon two theoretical frames (rational and cultural) to advance our argument about university governance. 


\section{A Rationalist Frame}

Many definitions of shared governance work from a rationalist framework. The rationalist frame is built on four basic assumptions that shape the nature of an organization's reality. First, rationalists assume that the organization is a reified entity that can be understood. Second, rationalists argue that an organization functions effectively through manifest meanings; all participants are able to interpret the organization in a similar manner. Third, they suggest that insofar as it is possible to codify abstract realities, one can then create generalizable rules for governance. Fourth, they assume that since rules for effective governance exist, organizational life can be predictable (Tierney, 1987).

Rationalist beliefs circumscribe organizational life and have important implications for the manner in which one thinks about and participates in shared governance. If an organization "exists" as an entity then the manner in which one tries to create change is through structural reconfigurations. One might think of an organization as a mechanism with multiple structures. Structures exist to create and maintain an effective and efficient organization. When one wants to improve decision-making the challenge is to figure out how to improve the mechanisms. From this perspective an organization's actors need an "owner's manual" of sorts that explains to them how the organization functions and what needs to occur when the structure does not do what it is supposed to do. The personalities and beliefs of those who participate in the organization are relatively unimportant in the rationalist framework. What matters is the ability of the individual to diagnose what is wrong with the structure and to fix it.

From a rationalist perspective, shared governance generates two assumptions. On the one hand, scholars define shared governance as the cooperation of various campus constituencies - namely the board, the president, the administration, and the faculty - in making decisions concerning the direction of an institution (Mortimer \& McConnell, 1978; Ramo, 1997; Schick, Novak, Norton, \& Elam, 1992). On the other hand, scholars write of shared governance as independent decision-making in which different issues belong to specific constituencies (American Association of University Professors, 1966; Kezar \& Eckel, in press). That is, the board holds fiduciary responsibility, the president manages the campus and decides on executive matters, and the faculty oversee the curriculum. Both views ring true and overlap with one another for those who work at postsecondary institutions. Shared governance does, in part, pertain to multiple constituencies "sharing" responsibility for decision-making. The survey referred to above also pointed out that there is wide agreement that faculty have a substantial say in academic matters - curricula, admissions requirements, promotion, and tenure criteria-but relatively little authority in fiscal matters. 
The concern with a rationalist frame of shared governance is particularly germane insofar as a great deal of discontent is voiced about the shortcomings of shared governance (Amacher \& Meiners, 2002; AGB, 1996). From a rationalist perspective the structures of decision-making have become inadequate for the fast-paced needs of the 21 st century. What needs to be done is to overhaul the structures of decision-making. The critics' concerns are that shared governance is messy and slow-one is never quite sure who decides what on a particular issue, and when faculty are involved in decision-making an endless round of debate ensues so that a logjam occurs. These critics suggest that the way to fix the situation is to clarify who decides what and to lessen the role of the faculty in decision-making.

However, shared governance is not an enumerated list that transcends institution and context. We will argue that those who seek to improve shared governance ought not to define governance from a rationalist perspective, for any such definition is foreshadowed by the surrounding contexts and actors. The challenge is to work through the cultural meanings of shared governance and consider how those meanings lead to institutional quality.

\section{A Cultural Frame}

The underlying premise of a cultural perspective is the need to constantly interpret the environment and the organization to internal and external constituencies. The organization is a social construct that undergoes transformations and reinterpretations based on dynamic contexts and the constant entry and exit of individuals. If a key determinant of governance is interpretation, then how one thinks of governance changes over time. All acts are interpretive and dynamic.

If an organization's participants think of governance as symbolic and interpretive processes devised to achieve particular outcomes as determined by the institution's actors, what are the implications of sharing this perception? As we elaborate in the case study, our point here is not that governance should be what it once was, or that governance is simply a ritualistic interaction that allows a cacophony of voices to be heard. Instead, we argue that understanding governance from an interpretive perspective enables individuals to develop culturally specific definitions of organizational mission and quality, which in turn, helps determine effective governance processes.

One flaw of some analyses that employ a cultural framework is the assumption that the purpose of studying culture is little more than enabling a Babel of voices. We suggest that when one works from a cultural perspective, the ability to come to terms with how quality might be improved within 
an institution becomes manifest in the processes, dialogues, and symbols of the organization. In addition to considering structural reforms, it is important to determine how to generate open discussion to achieve particular agreed-upon ends that will improve the quality of the institution. How one reaches agreement depends upon the culture in which one resides. Thus, from a cultural perspective, simply because structures exist and they appear to be in working order does not enable an organization's actors to claim that governance works. Instead, an organization's participants need to ask: What kind of governance processes ought to exist so that institutional quality occurs?

What are the indicators one might employ in judging the strengths and weaknesses of the governance processes of a particular institution? The answer to such a question goes well beyond bemoaning or celebrating an organization's academic senate, faculty involvement, or a strong board of trustees. Instead, the answer pertains to how one might gauge the effectiveness of these bodies in relation to institutional quality. If a cultural framework for governance is in a constant state of creation and recreation, then on-going reflective dialogues and debates need to focus on who is involved in governance, what particular structures are used, and how much authority one or another constituency has. The collegial assumption of consensus is dropped in favor of a cultural model of creative conflict. Cultures are not consensual; different individuals and groups will have different perspectives. Cultures also are not monolithic, so it stands to reason that governance structures will not be uniform. Power in an organization is variable and shifts due to an organization's history, culture, and current contexts. In what follows we elaborate on these ideas using a case study of a small private university.

\section{GOVERNANCE AND CULTURE}

\section{METHOD}

We conducted a case study of a single institution. A case study approach is a useful method for this investigation given that significant contextual relevance can be diluted during cross comparisons (Bogdan \& Biklen, 1992). Pleasant University (PU) was selected as a part of a larger study on academic governance. While visiting Pleasant University, we interviewed 22 members of the campus and held subsequent interviews with key informants. Interviewees were identified with the help of a PU staff member and according to criteria set by researchers such as the informant's role in governance. We sought individuals who had been at the institution for many years and those who were newcomers, as well as faculty from multiple disciplines in order to 
gain diverse perspectives on governance. To enhance trustworthiness we conducted hour-long interviews with campus members who represented a cross-section of perspectives and vantage points on governance (Glesne \& Peshkin, 1992). Interviewees included the president, provost, leaders of the university Assembly (the formal faculty governing body), deans, junior and senior faculty, and faculty from the humanities, social sciences, and professional schools. We also made sure to interview a mix of male and female faculty. In addition to interviews, we collected and reviewed campus documents. These include faculty handbooks, presidential speeches, strategic plans, and minutes from meetings in which decision-making took place.

In keeping with a cultural framework, we employed an interpretive perspective; intentions, circumstances, and actions were carefully considered and filled with multiple meanings (Denzin, 1988). This perspective is not predictive; it seeks to make sense out of social interaction within a particular context. We analyzed and coded the data using a grounded theory method which sought to develop themes inductively through a constant comparison of data (Glaser \& Strauss, 1967). We now turn to an overview of Pleasant University and then consider how governance functions.

\section{PLEASANT UNIVERSITY}

Founded at the turn of the 20th century, Pleasant University is a private liberal arts and science university that offers more than 40 undergraduate programs and grants masters degrees in limited areas. PU enrolls more than 4,000 students and has a 12:1 student/faculty ratio. Located in the western United States, the University is sprawled across an exceptionally beautiful campus populated with lush lawns and tall leafy trees. Over the past 10 years, PU has invested over 90 million dollars in the physical plant. "When people arrive on campus we want them to be impressed and get the message that we're a serious university," the president remarked.

The campus has a small-college flavor of a previous era. An interesting paradox emerges from reports of faculty and student demographics. The student body is more diverse than most institutions in its class. Among 3,015 undergraduates more than $13 \%$ identify themselves as Latino, $7 \%$ African American, and $13 \%$ report race unknown. Almost $60 \%$ of the undergraduates report they are white, and 6\% are Asian American. There are roughly 133 faculty, 83\% of whom are white or Asian American, and 7\% are either African American or Hispanic.

The university has a college of arts and sciences, a school of education, and a school of business. The schools of business and education are new, a result of a recent reorganization. About two thirds of the 133 faculty are in the college of arts and sciences. The new deans of business and education are charged with securing accreditation and are developing those schools. 
As one might imagine, the new schools have encountered resistance in their pursuits because many university constituents hold fast to the historical emphasis on liberal education.

Traditionally, the nature of faculty work at PU involves teaching up to six courses a year, service, and, to a lesser degree, research. Teaching is viewed as the cornerstone of faculty work. Service is viewed as a critical component of the culture and is necessary to secure tenure. "Service is a must for getting tenure here. There is a strong expectation that you should be involved, and people know who you are," one faculty member explained. "We don't want new professors to be preoccupied with service," added a second person, "but we always make sure they're on some committees so they get known, get to know the place." "I'd tell a new hire don't shirk your service," added another. "We talk about service mattering," summarized a fourth person. "You need to get involved beyond your department."

Over the past decade faculty work has increasingly involved research as the institution attempts to grow and compete with peer institutions for prestige and constituent advantage. This new direction is expressed most visibly in the recently revised faculty handbook. "In the last few years there has been an apparent emphasis placed on conducting research. This will change the nature of faculty work and modify what faculty spend their time doing" stated a faculty member of 32 years. "Research is now more important," added another, "but it's still a distant third in terms of priorities."

Service to the university seems to have been embedded in the culture, in part because of the small-town flavor of the surrounding town. However, the town has grown and is now less of a "small town." There is also an increase in faculty who live outside of the local community. "Fewer people live here," bemoaned one individual. "People used to be on campus all the time. It was expected, but now people live further away and don't come as much." An additional person explained, "Two-career marriages make living here difficult. So people commute here to work, and it's changed the place some."

For some, the move away from the local community has meant a weakening of the academic community. "People are less willing to get involved because when they come here their day is packed," stated one person. A second added, "It's understandable. It's happening everywhere. But we just have less time." "Email has replaced face-to-face," opined a third person. "They're all interrelated. People live an hour away, and they use email to get their work done. But it's impacted our sense of service, what governance means. It's not terrible. Times change."

For now, the president of 16 years and the vice president of 10 years provide a sense of institutional stability. Additionally, the university employs many long-time faculty committed to teaching and to liberal education sustaining and reinforcing the culture that holds together the community. 
Over the past decade PU has experienced minimal growth in the population of students or faculty. The university is built upon a foundation of community, teaching, service, and sturdy leadership. This foundation is about to change.

\section{GOVERNANCE AT PU}

The campus governance structure is comprised of a 36 -member board that has the traditional responsibilities of overseeing the financial, investment, and personnel matters of the university. The president has garnered a great deal of support from the board, providing him broad leeway in decision making. The president holds weekly cabinet meetings that include the vice presidents and deans.

Faculty participate in governance mainly through the Academic Assembly. Approximately $60 \%$ of the faculty attend each assembly. The assembly was recently restructured to accommodate the new schools and reduce the number of committees; it meets once a month. Additionally, each school has an assembly that governs matters pertinent to the college and presents issues of concern to the larger assembly. There has been a gradual shift toward more involvement at the school level rather than at the university level. Although the assembly is seen as the most important governance structure on campus, when coupled with the creation of the schools (business and education) and the decrease of individuals living in the community, all-campus governance as defined by primary involvement, and attendance in the assembly seems less strong today than a decade ago.

We selected the pseudonym "Pleasant University" for this case study based on the way members of this community expressed satisfaction with the governance of the campus that in turn creates a sense of contentment with campus life in general. "People sense that the administration is trying to do the right thing," explained one person. A second added, "We're listened to, and I suppose we all recognize that we give more advice than consent, but that's ok. We're moving in the right direction." The faculty expressed high levels of satisfaction with their work conditions and the management of the campus. We were hard pressed to find disgruntled members. "Things are good here," one faculty member remarked. Another exclaimed: "This is an extraordinarily civil campus. People get along and there is a sense that everyone wants what's best for the university." "Angry outbursts or yelling are extremely rare," said another, "It's not that we wouldn't tolerate disagreement. We do! It's that most of us feel that things are pretty good." The ethos of PU is marked by civility and courtesy reminiscent of mid-America in the 1950s.

The culture of governance at PU is based on trust and deference to the administration. The trustees are viewed primarily as ambassadors that 
help raise money. The senior administration - the president in particularrepresent the locus of authority on the campus. The faculty voice is represented mainly through the University Assembly but essentially it exists as an advisory body. Decision-making authority is freely granted to the president and there are few occasions where differing opinions are represented formally.

When asked about whether they had a good governance structure, the participants generally agreed based on deferential relations. Individuals' comments painted the picture of effective decision-making but did not clearly delineate what good governance meant other than that people agreed with one another: "Yes, governance works here. Everyone gets along," said one person. A second added, "Governance is always dicey on any campus, but the faculty respect the president and the vice president, so it's pretty good, yes." A third noted, "It hasn't always been good, but for a very long time we've cooperated with one another. This president's administration has focused on good relations with the faculty." And a fourth person summarized, "Governance succeeds when faculty and administration work together. That's what we've got." Thus, the members defined governance not by outcomes, such as an increase in quality. Instead, good governance meant the faculty and administration enjoyed cordial relations with one another.

\section{DECISION MAKING AT PU}

Every summer after commencement the president takes the vice presidents and deans away on a 2-day retreat to evaluate the past year and to plan for the upcoming year. "During this time I ask each of them to really think about where we are and how we can improve," said the president. By July each of the deans and vice presidents are asked to submit written ideas about the direction of campus. "During that process I ask them to talk about their ideas informally to different people across the campus," the president further explained. In August the group meets again to present ideas and compile a plan that will guide the campus. "Afterwards any faculty member or board member can call me and comment on the plan," said the president. The plan is published in October and serves as the administrative agenda for the year.

One person commented on the process by noting:

There is a veneer of decision-making on the part of the faculty. We're told a certain number of positions exist, and we can then decide with the provost what we should do. But that's a predetermined decision. Who's to say that we can only hire three new faculty this year? Other decisions lead into that one, but we're not involved in those. It's like 
the table is set and we get to choose where we want to sit. But who decided to set the table with that many chairs?

Other individuals also commented that faculty participation "was not as significant" as they'd like and that "the president has broad authority," but individuals appeared content. The portrait was neither of an individual who governed through intimidation nor a faculty that was disengaged. Rather, individuals were content with the direction the institution because they largely trusted the president and his staff even though some might have desired a bit more influence. "He has developed a reservoir of support through the years," said one person. "It's not hero worship," said another, "It's just that we understand the system and it appears to work. What's the problem?"

The creation of two new schools and the revisions to the faculty handbook were the most frequently mentioned recent changes. Both initiatives came from the administration. When asked about the faculty's role in creating or rejecting major initiatives one professor responded: "Minutes ago in the Assembly meeting, we were just verbally contemplating the issue of how much power we actually have. The problem I saw was that few Assembly members could answer the question."

"The plan to create the schools of education and business were fashioned before the faculty were asked about it," one professor stated. The process of decision-making at PU involved what one Assembly member called "selective consolation" by the president. The decision to create the new schools was announced by the administration. Many faculty members recalled that announcement as the first time they had heard of the restructuring. When asked about the faculty's response to the decision to create two new schools, an education professor explained that "there was not much reaction to the decision. The faculty just went about doing the work of getting it done without having much to say." A former dean recalled: "The faculty in many of the programs that would be moved into one of the schools were not even consulted during the process of decision-making." Yet when asked about the decision to create the schools of business and education, once again many faculty expressed satisfaction and concern but did not mention disappointment with the process of decision-making. A business professor remarked:

The president has a good track record with the faculty, and most people trust him to do the right thing. Some people had questions about creating new schools but those voices were so faint that the administration didn't hear them. I would say that people are just accustomed to the president making decisions. Most faculty don't really 
seem to mind and the few willing to challenge him recognize that they are the minority.

The Academic Assembly was viewed as an information-sharing venue more than a governing body. A long-time English professor expressed little confidence in the assembly's ability to influence decisions: "the Assembly is useful for information but it has no power." An assistant to the vice president stated that "the Assembly is sort of a show and tell that is manipulated by the administration. I even remember a faculty search that was manipulated by the administration as an example of just how compliant they [faculty] can be." Of interest is not simply the individual's comment but the manner in which it was said. When some individuals comment that something is a "show and tell" it is often said to demonstrate distrust and dissatisfaction. However, this speaker, as many other interviewees, expressed little unhappiness. Faculty and administration were aware of the processes of governance and appeared content.

Revising the faculty handbook into "the handbook for faculty" was another example of an action in which the administration led the changes. A member of the assembly recalled:

Originally the faculty were charged with revising the handbook. There were some things that really needed to be changed but like most places the faculty fumbled around with [the handbook] never being able to get it done. The provost then headed up the process which was fairly contentious at times. What was interesting to me is that as the process went along you could see the administration positioning itself to take decision-making authority out of the hands of the faculty. Ironically, the handbook for faculty, as it's now called, is the document that puts into effect these changes.

Others agreed that revising the handbook was a process that involved the faculty and administration in an adversarial relationship. "Everyone has a story. Some will blame the vice president and others one or another professor. What's important, though, is that we resolved them. We worked through the process. The vice president deserves credit." "It's an example," claimed another, "of one of those things that could have gone either way. It could have ended badly, but I think the history of how we work with one another saved us." They also agreed that the process was "at times litigious" because of changes to the tenure requirements which placed a slightly greater emphasis on research and changes to the salary structure. Still, faculty accepted the fact that the administration, and to some extent the board, exerted decision-making authority without much consultation of the faculty. 
In spite of widespread satisfaction with governance many faculty were of the opinion that they did not have "real" power. "The faculty, at best, serves an advisory capacity and most people seem to be OK with that" one English professor stated. When asked about his relationship with the faculty, the president stated that "there's almost too much trust. I can set pretty strong agendas. People give me the liberty and will to do so." He then stated that "it's nice to be liked but it's more important to be respected and trusted."

A recent newcomer to the campus summarized the pervasive culture of deference by saying:

There is a structure that allows for dialogue but the president is so well liked that faculty defer their will and rights to him. It's an enormous display of trust. I've been here for two years and have been amazed at how central the decision-making is and even more amazed at how satisfied the faculty are with this kind of structure.

\section{QUALITY: NEW CHALLENGES AND CHANGES}

The challenges and changing environment facing PU likely will create a significantly different decision-making context from what currently exists. Almost $40 \%$ of the PU faculty, for example, will be eligible for retirement within six years. At the same time, the schools of education and business expect to undertake significant recruitment. The assistant to the provost explained:

We are really concerned about what our faculty will look like in the near future. With the changes to the university there is a concern that new faculty will care less about teaching and more about research and won't be concerned the least bit about service.

There are also concerns about socializing new faculty in the ways of PU according to a professor of philosophy and member of the campus for 15 years:

I fear that the faculty will turn over at such a rate that we won't be able to acculturate them or subject them to the type of social pressure to serve the way we once could. When I first got here there was an unspoken rule that to be a member of the community you had to be involved with the work of the campus. That's how you gained your acceptance. As we look to expand I don't think that we'll be able to leverage that kind of pressure. 
In addition to faculty turnover, concerns about a changing student population exist. Not only is PU expected to increase its traditional student population, it also intends to increase enrollment among professional students, which means holding classes at night and possibly on-line. "We were one kind of campus," said one individual, "and now we're becoming another." Another summarized: "You can't stay stuck in the past. But I hope as we get new students, new faculty, a new president and administration, there's still some of what makes us 'us' left."

We asked participants about the effects such changes might have on PU over the next 5 years. Most expressed a mixture of optimism and fear. It is a well-known fact that the president is nearing retirement. Additionally, the changes that will result from the new schools create a sense of uncertainty across the campus. The dean of one school commented:

I would bet on this place. If the president sticks around through the capital campaign you'll see that we've incorporated the new schools. We will grow our enrollments, move up in the rankings, and we'll have a more diverse student population in the professional schools.

Concerning governance, a professor of 33 years and chair of a school Assembly predicted:

I think you'll see that we've changed. The governance activity will be separate and I think that the faculty workload will change, which in turn affects the number of days people come to campus. This essentially means that we'll be a different campus.

The chair of the university assembly stated:

There will be a new president and administration. Governance for the most part will be secondary because people will be so busy with their work. What all of this means is that the university will be much more segmented and the culture of service at PU is at risk of being broken down into service for self and service for the school.

Another dean explained:

With the new schools there is going to be a need for more autonomy. For example, right now in order to make any purchase over $\$ 500$ dollars forms must pass through the administration for processing and approval. Well, you can't even buy a computer with $\$ 500$ dollars and it makes building a school difficult with those kinds of constraints in 
place. So my guess is that we are going to have to disburse much of the responsibility that once existed in the central administration down to the school level to enable us to do our work effectively.

Although some could point to changes, few were able to tie the future to an explicit sense of quality or excellence. Rather, most individuals talked about the environment from a rationalist perspective and suggested ways that the organization might react to the change. Faculty will retire and new faculty need to be hired. Schools need to grow and there will be autonomy. A president will retire. Although many of these issues are social "facts" in the sense that they will occur, what one did not hear at PU is how individuals tied change to any explicit sense of organizational excellence.

When asked, for example, where the institution will be in 5 years, one person said: "We'll be bigger, that's for sure. I can't predict much more." Another stated, "I hope we still have a fairly inclusive structure, not hierarchical." A third person commented on structures: "We need to figure out how to get the committee work under control; the faculty review process is unwieldy." Another faculty member said, "We'll be pretty much the same. We're pretty satisfied with what we're doing now." A final person predicted, "We'll be about what we are today. I sure hope we are."

What might one make of such an institution's culture and how governance functions within it? On many levels, the institution appears strong. Campus facilities are attractive and abundant. Basic indicators such as enrollment, endowment, completion rates, and student satisfaction are good when compared to peer institutions. The faculty respect the administration and the administration asks for input from the faculty on many issues. The structures of governance appear to be what exist on manifold campuses-departments, schools, and a campus-wide governing body- and they entertain typical issues such as revisions to the faculty handbook, curricular reform, and issues pertaining to student life. The vitriol and suspicion that marks many campuses is absent. Thus, one might conclude that Pleasant University is a campus where governance works. People respect one another, and from that respect comes a culture that enables the institution to move forward. In what follows, however, we offer a caution and expand on the notion of governance as a culturally mediated process.

\section{ORGANIZATIONAL CULTURE AND THE DANGER OF DEFERENCE}

Pleasant University is a campus where individuals trust one another, and the administration and the faculty have exceedingly cordial relations. Trust 
and civility are important precepts of sound governance (Kramer \& Tyler, 1996; Tyler \& Huo, 2002). Indeed, distrust is often associated with failed governance systems. Pleasant University, in many ways, is a model campus for communication and trust between campus constituents. One professor proclaimed: "I guess we are more efficiently run as a result of the president's ability to make decisions and our trust that he'll do the right thing." Common sense suggests that fundamental trust and civility among members of any organization is useful for progress. We do, however, wish to suggest that trust and civility alone are not sufficient criteria to enable quality to occur.

While a culture of trust and deference may enable individuals to "get along" in the words of one individual, simply because different groups trust one another does not ensure quality. Indeed, sometimes to create the conditions of quality an organization's structures need to ensure that thoughtful dialogue and debate will ensue. We are suggesting that a culture of trust needs to be something more than everyone simply deferring to leaders. Governance needs to be linked to an increase in institutional quality rather than simply a series of harmonious structures. At PU, those very structures that might enable debate are under-utilized. In the words of one faculty member:

Although the Assembly exists, it doesn't have power to do anything. The president and the administration really run the place. What's amazing is [the president] has, for the most part, made decisions that the faculty can live with. Although we may not like something, there is not much discussion about it and no real prescribed steps to do anything about it. I guess that's the down side of entrusting a campus to the president and his administration. For this very reason a lot of people will be nervous about the selection of his successor.

An additional concern is whether the current structures are able to accommodate conflict and disagreement. The lone example from the recent past when the faculty and president could not agree over an issue is illustrative. A faculty member explained:

For a long time there has been discussion about moving our interim session. The decision went to the Assembly but the faculty could not make any decision about what to do with it. Finally the president decided for them. The interim session is important to many faculty here for a number of reasons. Well, the faculty were dissatisfied with it being moved to the summer and many have decided not to participate. Since the move we have had trouble with that session because many faculty refuse to teach. 
A rare faculty disagreement with the decision of the president provided the campus with a glimpse of the current strengths of their culture and the potential dangers of deference. On the one hand, the president was able to implement an idea without a faculty vote because they trusted him. On the other hand, over the past decade PU has experienced few decisions that create disparate positions. Some governance scholars have mistakenly assumed that a productive organizational culture is one where individuals agree with one another, as if cultures are communicative entities in which individuals interpret actions from a similar perspective. We suggest that inclusive decision-making structures that are based on trust in individuals and trust in an established process need also to legitimize contentious decision-making.

Our point is delicate; we are not suggesting that an organization's culture should be one that is distrustful. However, the opposite is also incorrect. Simply because everyone trusts a long-time leader does not ensure organizational quality. From this perspective, is PU well situated for the future? They have the conditions for quality to arise insofar as the culture is one of trust. Rather than focus on rationalistic changes that are sure to occur-the retirement of the president, and the like-we are suggesting that the organization's participants will be well served if they concentrate on cultural values and how discussions about values might enable the promulgation of quality.

Consonant with the issue of decision-making culture is faculty responsibility. Two instances of important decision making at PU were assigned to the faculty. The revising of the faculty handbook and changing the interim session were both issues originally sent to the Assembly for faculty to decide. In both cases the PU faculty admit to being unable to forward a resolution. "The faculty fumbled around with the [handbook]" said one member of the Assembly. Another commenting on the interim session stated that "the faculty could not make any decision... Finally the president decided for them." In the interest of promoting cultural values that ensure institutional quality, faculty are obligated to assume responsibility for making informed and timely decisions. The inability to do so can silence faculty voice in decision making and further compromise institutional quality.

\section{CONCLUSION}

We have argued here that a rationalist framework assumes reality as objective and understood whereas a cultural frame assumes that organizational reality is created. While such a comment is not surprising, we then pointed out that the implications for governance are quite different. The rationalist assumes that structures exist that can be improved to create more 
efficient and effective decisions, whereas proponents of a cultural approach suggest that governance exists through the communicative and symbolic processes of the organization. We then suggested that trust among individual campus constituents provides the scaffolding for effective systems of governance, but that trust alone is an insufficient variable to increase organizational quality. Trust is a process rather than an end.

The case of PU highlights the dilemma of deference. The president at $\mathrm{PU}$ is of the opinion that the faculty trust him too much. This, in some ways, signifies not so much an abandonment of faculty responsibility, but the danger of a culture where trust is seen as an end in and of itself. Neither the president nor the administration was characterized as autocratic. Instead, a culture has been created where "getting along" has been at a premium. Our concern is not that trust is useless, but rather that, in a time of change, organizations need to develop cultures that have the expectation of improving quality. In order to improve quality, individuals need to create and sustain ways to effectively engage one another about what the institution's goals are and how to reach them.

Campuses with deferential systems of governance might examine the expectations of the faculty. Although the PU faculty were service oriented, their service involved carrying out decisions of the administration. Faculty more meaningfully involved in decision-making might likely assert themselves as responsive partners in campus governance rather than as workers.

Governance needs to be more aimed at improving organizational quality than with placating constituencies. The case of Pleasant University serves as one example of the potential dangers of a culture based on agreement. In the development of understanding governance, a consideration of the cultural and structural aspects of an institution is always useful, particularly during times of change. The importance of trust, the issue of faculty responsibility, and the matching of cultural processes with an organization's structures, represent areas that provide significant insight to the understanding of the complexities of governance.

This case also serves as an example of the need to create governance systems and cultures able to withstand transitions. Many of the PU constituents were concerned about what will happen when the current president retires which indicates that their confidence is based on the current collection of personnel. We suggest that effective governance systems are related to personnel but should transcend individuals. As it stands, PU faculty are without effective formal mechanisms that support their involvement in governance. Additionally, the institutional transition will likely incite disagreement, increased autonomy, and a more ambiguous mission - all factors for contentious decision making.

The culture of decision making is then complimented by structural mechanisms that reinforce the values of a campus community. Scholars 
often discuss structure to the exclusion of culture or vice versa. Although our focus here is on culture we do not intend to suggest that structure does not matter. Instead the two (culture and structure) should reflect one another and not been seen as exclusively separate. A cultural perspective helps us view academe from one angle but effective systems are comprised of balance between both cultural values and flexible structures that support them.

The authors wish to thank Vince Lechuga for his work on this article.

\section{References}

Amacher, R., \& Meiners, R. (2002). Free the universities: Reforming higher education to keep pace with the information age. San Francisco: Pacific Research Institute for Public Policy.

American Association of University Professors. (1966). Statement on government of colleges and universities. (AAUP). Retrieved, October 18, 2004, from http://www.aaup.org/statements/ Redbook/Govern.htm.

Association of Governing Boards of Universities and Colleges. (1996). Renewing the academic presidency: Stronger leadership for tougher times. Washington, DC: Author.

Baldridge, J., Curtis, D., Ecker, G., \& Riley, G. (1977). Alternative models of governance in higher education. In G. L. Riley \& J. V. Baldridge (Eds.), Governing academic organizations. Berkeley, CA: McCutchan Publishing Corporation.

Baldwin, R., \& Leslie, D. (2001). Rethinking the structure of shared governance. Peer Review, 3(3), 18-19.

Benjamin, R., \& Carroll, S. (1999). The implications of the changed environment for governance in higher education. In W. G. Tierney (Ed.), In responsive university: Restructuring for high performance (pp. 92-119). Baltimore: John Hopkins Press.

Birnbaum, R. (1988). How colleges work: The cybernetics of academic organization and leadership. San Francisco: Jossey-Bass.

Bogdan, R., \& Biklen, S. (1992). Qualitative research for education. Needham Heights, MA: Simon and Schuster.

Carlin, J. (1999, November 5). Restoring sanity to an academic world gone mad. The Chronicle of Higher Education. Retrieved September 3, 2002, from http://chronicle.com

Clark, B. (1970). The distinctive college. Antioch, Reed, and Swarthmore. Chicago: Aldine.

Cohen, M., \& March, J. (1974). Leadership and ambiguity: The American college president. New York: McGraw-Hill.

Denzin, N. (1988). The research act (Rev. ed.). New York: McGraw-Hill.

Glaser, B. G., \& Strauss, A. L. (1967). The discovery of grounded theory: strategies for qualitative research. Chicago: Aldine Publishing.

Glesne, C., \& Peshkin, A. (1992). Becoming a qualitative researcher. White Plains, NY: Longman.

Kezar, A., \& Eckel, P. (2004). Meeting today's governance challenges: A synthesis of the literature and examination of a future research agenda. Journal of Higher Education, 75(4), 372-399.

Kramer, R. M., \& Tyler, T. R. (1996). Trust in organizations: Frontiers of theory and research. Thousand Oaks, CA: Sage.

Kuh, G., \& Whitt, E. (1988). The invisible tapestry. Culture in American colleges and universities (ASHE-ERIC Higher Education Report No.1). Washington DC: Association for the Study of Higher Education.

Masland, A. (1985). Organizational culture in the study of higher education. The Review of Higher Education, 8(2), 157-168. 
Mintzberg, H. (1979). The professional bureaucracy. In H. Mintzberg (Ed.), The structure of organizations (pp. 348-379). Englewood Cliffs, NJ: Prentice-Hall.

Mortimer, K., \& McConnell, T. (1978). Sharing authority effectively. San Francisco: Jossey-Bass.

Peterson, M. (1985). Emerging developments in postsecondary organization theory and research: Fragmentation or integration. Educational Researcher, 14(3), 5-12.

Ramo, K. J. (1997). Reforming shared governance: Do the arguments hold up? Academe, 83(5), $38-43$.

Schick, E. B., Novak, R. J., Norton, J. A., \& Elam, H. G. (1992). Shared visions of public higher education governance: Structures and leadership styles that work. Washington, DC: American Association of State Colleges and Universities.

Sitkin, S. B., \& Stickel, D. (2002). The road to hell: The dynamics of distrust in an era of quality. In R. M. Kramer \& T. R. Tyler (Eds.), Trust in organizations: Frontiers of theory and research. Thousand Oaks, CA: Sage.

Tierney, W. G. (1987). Facts and constructs: Defining reality in higher education organizations. Review of Higher Education, 11(1), 61-73.

Tierney, W. G. (in press). A cultural analysis of shared governance: The challenges ahead. Higher education: Handbook of theory and research.

Tierney, W. G., \& Minor, J. T. (2003). Challenges for governance. Los Angeles: University of Southern California.

Tyler, T., \& Huo, Y. (2002). Trust in the law. New York: Russell Sage.

JAMES T. MINOR is an Assistant Professor of Higher Education in the HALE program at Michigan State University. His research interests include higher education policy, governance, and issues related to HBCUs. His recent publications include "Understanding Faculty Senates: Moving from Mystery to Models" (The Review of Higher Education, 2004, 27(3)) and "Dilemmas of Decision-making in Historically Black Colleges and Universities: Defining the Context" (Journal of Negro Education, 73(1)).

WILLIAM G. TIERNEY is the Wilbur Kieffer Professor of Higher Education and Director Center for Higher Education Policy Analysis at the University of Southern California. His research interests pertain to governance, faculty productivity, and issues of equity. His recent publications include Competing Conceptions of Governance: Negotiating the Perfect Storm (Baltimore, MD; Johns Hopkins Press, 2004) and From High School to College: Evaluating Access with Zoë Corwin and Julia Colyar (Albany, NY: State University of New York Press, 2004). 
Copyright of Teachers College Record is the property of Blackwell Publishing Limited and its content may not be copied or emailed to multiple sites or posted to a listserv without the copyright holder's express written permission. However, users may print, download, or email articles for individual use. 